\title{
Toothpaste Sign in Thyroid Surgery
}

\author{
Mayilvaganan Sabaretnam ${ }^{1}$, VNSSVAMS Mahalakshmi D ${ }^{2}$, Suneel Matoo ${ }^{3}$, Amit Agarwal $^{4}$
}

\begin{abstract}
Toothpaste sign is imparted by the fine vaso nervosum running over the white RLN resembling a popular toothpaste.

Keywords: Thyroid gland, Thyroid malignancy, Thyroid, Toothpaste.

World Journal of Endocrine Surgery (2020): 10.5005/jp-journals-10002-1286
\end{abstract}

\section{Dear Sir,}

We want to report the toothpaste sign in thyroid surgery which may interest thyroid surgeons and surgical trainees.

A 28-year-old lady underwent a completion thyroidectomy for follicular variant of papillary thyroid carcinoma, and during the lateral approach for completion of thyroidectomy, we encountered the recurrent laryngeal nerve (RLN), and the RLN nerve had classic toothpaste sign (Figs 1 and 2). ${ }^{1,2}$

Toothpaste sign is imparted by the fine vaso nervosum running over the white RLN resembling a popular toothpaste.

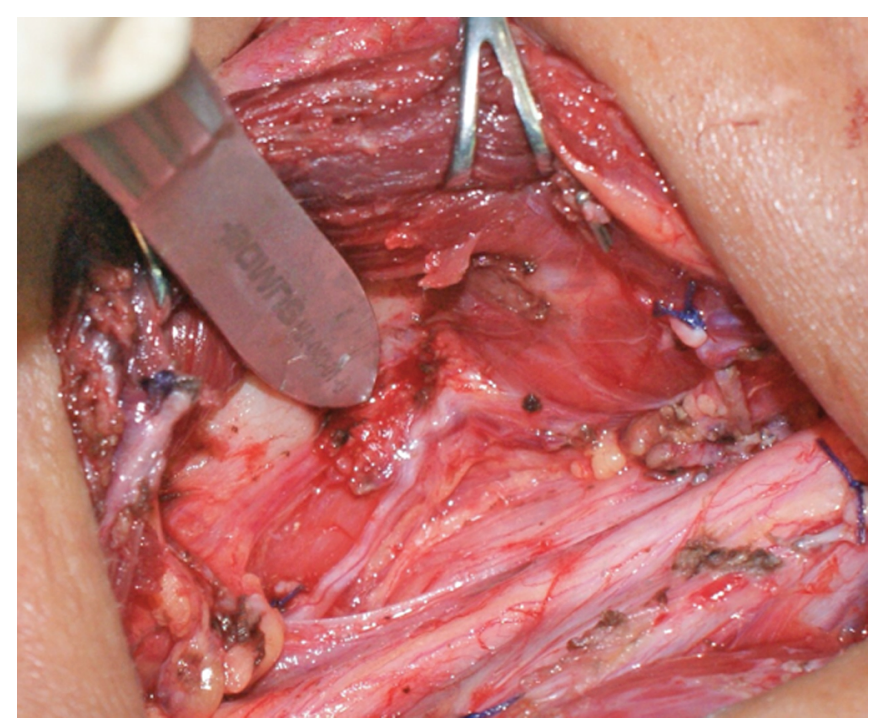

Fig. 1: Recurrent laryngeal nerve with fine blood vessel resembling toothpaste

\section{References}

1. Agarwal A. Atlas of Thyroid Disorders and Thyroid Surgery. 1st ed., New Delhi: Jaypee; 2013. p. 121.
${ }^{1-4}$ Department of Endocrine Surgery, Sanjay Gandhi Postgraduate Institute of Medical Sciences, Lucknow, Uttar Pradesh, India

Corresponding Author: Mayilvaganan Sabaretnam, Department of Endocrine Surgery, Sanjay Gandhi Postgraduate Institute of Medical Sciences, Lucknow, Uttar Pradesh, India, Phone: +91 (0522) 2668004-8 extn 3200, 2668777, e-mail: drretnam@gmail.com

How to cite this article: Sabaretnam M, Mahalakshmi DVNSSVAMS, Matoo S, et al. Toothpaste Sign in Thyroid Surgery. World J Endoc Surg 2020;12(1):45.

Source of support: Nil

Conflict of interest: None

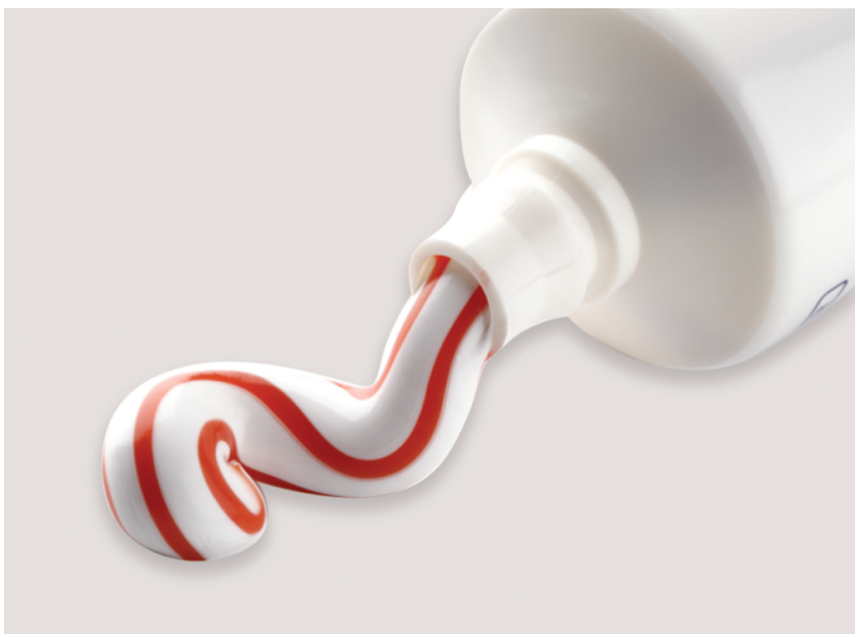

Fig. 2: Popular toothpaste

2. Bothra S, Sabaretnam M, Kannujia A, et al. Patient, thyroid, and surgeon related factors that make thyroidectomy difficult-cohort study. Ann Med Surg 2019;49:14-18.

(C) The Author(s). 2020 Open Access This article is distributed under the terms of the Creative Commons Attribution 4.0 International License (https://creativecommons. org/licenses/by-nc/4.0/), which permits unrestricted use, distribution, and non-commercial reproduction in any medium, provided you give appropriate credit to the original author(s) and the source, provide a link to the Creative Commons license, and indicate if changes were made. The Creative Commons Public Domain Dedication waiver (http://creativecommons.org/publicdomain/zero/1.0/) applies to the data made available in this article, unless otherwise stated. 